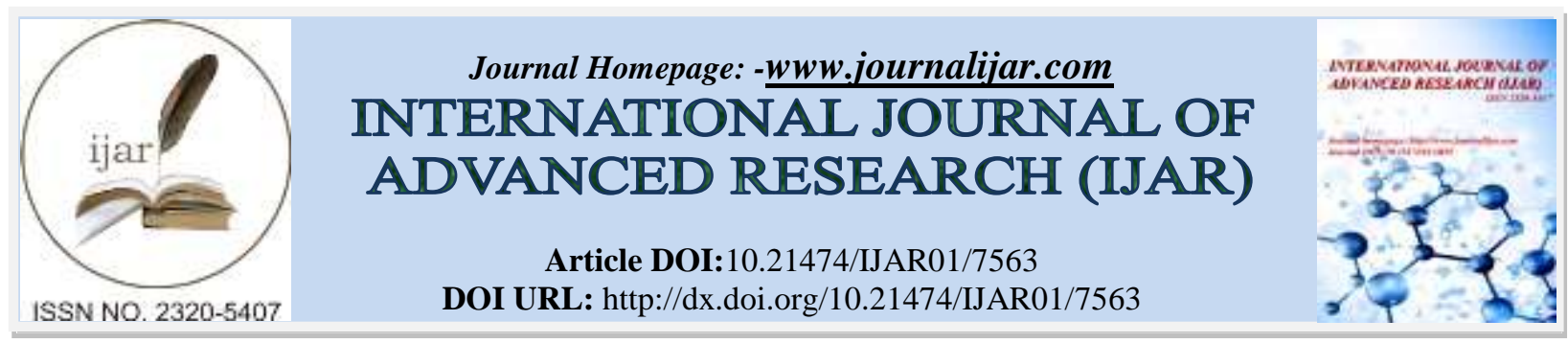

RESEARCH ARTICLE

\title{
GENDER DIFFERENCES IN ATTITUDE TOWARDS TEACHING AND LEARNING OFMATHEMATICS IN SENIOR HIGH SCHOOLS OF CAPE COAST METROPOLIS.
}

Laud TeyeNartey (PhD Candidate).

OLA College of Education, Cape Coast.

\section{Manuscript Info}

Manuscript History

Received: 14 June 2018

Final Accepted: 16 July 2018

Published: August 2018

Keywords:-

Difference, Gender Attitude and

Mathematics Achievement.

\section{Abstract}

The paper explored gender difference in attitude toward teaching and learning of mathematics in Senior High Schools of Cape Coast Metropolis. This subject was conceived from gender biases which could be observed from the West African Senior Secondary Examination (WASSCE) results over time. The study identified five attitudinal factors toward teaching and learning of mathematics: gender interest, gender confidence, gender fear, gender competence and gender success. Descriptive survey design was used coupled absolute performance differences between males (boys) and females (girls). Data were collected from three sub-groups: boys school, girls school and mixed school. Self-administered questionnaire with a four-point Likert scale was used. It was revealed that there is a gender based differences in attitude toward the teaching and learning of mathematics in the selected schools. The study found that males (boys) have more positive attitude toward mathematics than girls. This was observed in terms of gender interest, gender confidence, gender fear, and gender success. However, regarding gender competence, the findings showed that gender differences are inconsequential. It is suggested that more attention should be given to girls in mathematic class. Teachers of mathematics are encouraged to varying their teachings to accommodate these gender differences so that gender balance performance could be reached.

\section{Introduction:-}

Education is an anchor for the development of society and foundation for change. One important area of education which continuous to open up the world and creates the path for the future ismathematicseducation. Mathematics has proven to be imperative and fundamental for our society in terms of progress and success. It is an instrument for political,socio-economic, scientific and technological developments (Mutai, 2016). This does explain why mathematics and as it were core mathematics is a compulsory subject for all learners inprimary and secondary schools in Ghana.

It is therefore important for students of all levels especially the senior high schools to have a positive attitude and deep understanding of the concepts of mathematics from the beginning of their education. As society continues to become more reliant on technology, jobs are going to require a higher level of understanding of mathematical concepts. It is not surprising that all universities and other tertiary institutions in Ghanause mathematics as 
prerequisite for selectingstudents from senior high school for entry into virtually all degree programmes. Almost all public and private universities in Ghana require a least a pass in mathematics before admission could be granted to prospective applicant.It is important that everyone receives an equal educational experience in mathematics because of all of these realities.

There is no denying fact that most day to day decisions taken are based on such questions as 'what and how' and the likes.Logically, these questionsare better answered by converting every statement to mathematical statement before solutionis sought (Mohamed \&Waheed, 2011). This means that even in decision making, the depth of mathematical knowledge an individual has dictates the levelof accuracy of his or her decision. It further implies that before an individual canfunction well in the society, one must possess relatively good knowledge ofmathematics especially in this era of technological age. Having these thoughts,Boyer and Merzbach (2011)referred tomathematics as the central intellectual discipline of the technological societies. From a different perspective, English andKirshner (2015) describe mathematics as a language of science. Similarly, Battey (2013)argues that mathematics is not only the language of sciences, but essential nutrient forthought, logical reasoning and progress.

It could be concluded that mathematics is the basis of allsciences and technology and of all human endeavours. Application of mathematicscuts across all areas of human knowledge (Robinson \&Lubienski, 2011). It is therefore not surprising that almost all countries and for that matter Ghana, acknowledge perceived role of mathematics in scientific and technologicaldevelopment and recommends it as a compulsory subject in the secondary schoolcurriculum. The syllabus is designed in such a way that the knowledge and skillsacquired in one level become a prerequisite for the next level, for example, the lawsof statistics are arithmetic. Additionally, systematic learning of statistics shouldrequire the fundamental processes of arithmetic, namely; addition; subtraction;multiplication and division (Asante, 2012). Several studies (Devine, Fawcett, Szücs\&Dowker, 2012; Mohamed \&Waheed, 2011; Pahlke, Hyde \& Allison, 2014) suggestthat mathematics need not be learned by students in secondary for the sake of careerchoice or advancement but students should be able to learn mathematics withunderstanding and to apply mathematical ideas later in life

Notwithstanding the benefits of mathematics, gender which remains a dividing status between members of society affects its studies too (Battey, 2013).This explains why research entering on students' attitudes toward mathematics study has received increasing attention, and the most common explanations for gender disparities in mathematics achievement has focused on attitude that students have towards mathematics (Asante, 2012). In general, most of the studies reported that, compared with boys, girls lacked confidence, had debilitating causal attribution patterns, perceived mathematics as a male domain, and were anxious about mathematics (Mata, Monteiro\&Peixoto, 2012; Mohamed \&Waheed, 2011).

Theoretically, differences in attitudes in gender towards learning of subjects including mathematics is supported by the social cognitive, Eagly's social role theory and other gender developmental theories. The cognitive theory is an approach to psychology that attempts to explain human behavior by understanding thought processes of individuals (Stevens, 2013). The dominant aspects of cognitive theory involve the interaction between mental componentsand the information that is processed through this complex network. This means that, asindividuals (male or females) learn, they actively create cognitive structures which determine their concepts of selfand the environment (Beck \&Haigh, 2014). On the part of the Eagly's social role theory, theory that focuses on interactions between and among individuals,groups, societies, and economic systems as developed by social systems inwhich people live. At times, these social systems sometimes promote or detercertain people in maintaining or achieving health and well-being (Eagly\& Wood, 2011).These theories illustrate that gender differences exist due to a lot of social and environmental factors. These theoretical thinking could be to explain the differences and attitudes towards the study of mathematics.

Gender differences in attitude in mathematics do not have only theoretical connotations and significance but has also gain attention in empirical literature. For instance, Oludipe, (2012) in his study on gender differences in schoolingexperiences of adolescent in low income countries, noted that in low performingschools, teachers tend to think that mathematics is somewhat important for boys.According to Pahlke, et al (2014) and Mutai (2016),learning mathematics by girls may be inhibited by the presence of boys. Moreover, Mbuthia(2011) found that female students performed better than the male counterparts inmixed secondary schools, while male students recorded a better performancecompared to their female counterparts in single sex secondary schools. 
Concentrating on a different perspective, Ajai and Imoko (2014) in their research on mathematics self-concepts (MSC) and student'smotivation to learn mathematics (SMOT) conclude that students' mathematics self-conceptis related to their motivation to learn mathematics. Gender differences,favouring boys, exist in students' perception of likelihood of success, and satisfactionin learning mathematics. The researchers also concluded that students' MSC isdifferentiated by gender, school social setup and grade level and that girls in coeducational secondary schools have the least self-concept and motivation to learn mathematics. Furthermore, Kosgei and Bii (2007) in their research on gender differences andattitudes towards learning of mathematics among secondary school students foundthat both boys and girls have positive attitudes towards learning of mathematicsthough boys were more inclined than girls. Hlalele (2012) also stated that the femalestudents' attitude towards mathematics is more positive than the male students.Students' perceptions of parental, teachers and peer expectations were found tosignificantly influence gender differences and attitudes towards learning ofmathematics.

These empirical literatures give conflicting findings on gender attitude towards the study of mathematics. While some findings point to positive attitude from both males and females (Kosgei\&Bii, 2007; Mensah, Okyere, \&Kuranchie, 2013), others point to females as having positive attitude than that of their male counterpart (Hlalele 2012). Better yet other studies have found a significant difference between males and females towards mathematics (Ajai\&Imoko, 2014). Other studies have also showed that there is no significant difference between attitude towards mathematics among male and female students (Mata et al, 2012; Mohd, Mahmood\& Ismail, 2011). Some have also demonstrated that there is a difference between attitude in the lower level and when students get to upper level (Brown, Brown \&Bibby, 2008; Mohamed \&Waheed, 2011). A critical evaluation of these studies provides that students' attitude towards mathematics are very subjective and varies among the students. These inconsistencies need to be resolved to find out the direction of gender difference towards mathematics among students. However, in Ghanaian context, limited studies exist in this scope of studies.Most of the studies on student's attitudes towards mathematics have centred on Western samples, whilst very few studies (Asante 2010; Asante, 2012) have centred in Ghana.In spite of these inconsistent findings which needs additional research for clarifications, information on gender differences in attitude towards mathematics in SHS in Ghana is scanty. The few that exist too have concentrated on the causes of the differences in attitude more the general attitude (Asante, 2012; Kyei, Apam\&Nokoe 2011). Moreover, these studies have been explored in the Northern regions (Kyei, Apam\&Nokoe 2011) and in Accra (Asante, 2012). This means that in spite of the numerous secondary schools in the Cape Coast metropolis, these types research are still at their infantry (i.e. to assess gender differences in attitude towards mathematics) (Arhin\&Offoe, 2015). It is therefore important to assess the phenomenon in the Cape Coast metropolis as well.Cape Coast is the panacea of Secondary education in Ghana and houses a lot of High School. This makes it important to assess gender differences in attitude towards mathematics in among some Senior High Schools (SHS) in the Cape Coast metropolis.

\section{Theoretical Literature:-}

This paper is built from the social cognitive theory. This theory is explored to unearth attitudinal factors which may breed gender differences and influence gender attitude towards the study of mathematics. The social cognitive theory is a phenomenon in psychology that attempts to explain thought processes of individuals in order to understand human behavior (Stevens, 2013). The prevalent aspects of cognitive theory involve the interaction between mental components of students in their learning process and the information that is processed through this complex network.The social cognitive theory revolves around the notion that if we want to know what makes people think the way they do or behave in a particular direction then we need to understand the internal processes of their mind.

Cognition literally means "knowing". In other words, social cognitive refers to the study of human mental processes and their role in thinking, feeling, and behaving (Mazziotta, Mummendey\& Wright, 2011). Taking a prospective look at the learning and internal processes of the mind of students, the cognitive theory assumes that when such internal thinking is properly shaped, it helps the individual to be properly fit into whichever environment that such individual finds themselves. In the view of Clark and Beck (2010), shaping the thinking of individuals involves undertaking a comprehensive training and developmental process of such individuals.Inferring from the information above, it could be observed that the mental processes of individual who according to the definition of cognition aid in "knowing" stems from enabling environment.

Gender differences in attitude could create environment for differences in gender dispositions towards studying mathematics. This means that gender attitudinal differences could affect how students' cognitive power is shaped 
and subsequently affecting their attitude.Some of these attitudinal factors are gender interest, gender confidence, gender fear, gender competence and gender success.

\section{Empirical Review:-}

Within the northern sector of the country, Kyei, Apam and Nokoe (2011) examined the expected causes of gender difference in the performance of mathematics among boys and girls in mixed senior high schools in the Upper East Region of Ghana. Questionnaire and interviews were used for data collection. Results indicated that, boys' performances outweighed those of girls, as it was evident that girls' lack of self-confidence was a contributing factor or a major cause of the difference in performances. It was also found out that, students' interest in mathematics was influenced by personal interests and teaching methods.

On students' performance analysis, the class of the student, the number of educated people in the student's house and the sex of the student were found to be linearly related. Furthermore, perceived gender difference caused school drop-out and poor choices of girls relative to boys. It was inferred that, this aspect of the study, for gender equity in decision making cannot be achieved once gender difference in mathematics ability of boys and girls is not resolved. Also, the capacity to educate pupils from the elementary schools will remain incomplete as women always passed on these perception and belief to younger generation even before they start to make their own choice in academics. It could be observed that Kyei et al (2011) focused on the cause of gender differences among students in mathematics. The study failed to establish the differences before going on to investigate the cause of then differences. The current study extends the literature of Kyei et al (2011) by first examining gender difference and attitude towards the study of mathematics before any further study on the cause could be recommended.

In Kenya, Owiti, (2011) conducted a study using a sample of 205 form three students (126 girls and 79 boys) tried to investigate whether there was any significant gender difference in attitudes toward mathematics. Questionnaires and face to face interviews were used in data collection. Descriptive (\%) and inferential (chi-square and z-statistic) statistics were then used to analyse the data. The findings of the study indicated that more boys than girls $(93.7 \%$ of boys compared to $59.5 \%$ of girls) had positive attitudes toward mathematics while more girls than boys (35.7\% of girls compared to $6.3 \%$ of boys) were negatively oriented toward mathematics. Calculation of z-statistic confirmed that the difference between the two means was significant.

Chi-square calculation showed a significant relationship between sex of student and attitude held. Based on the findings, it was concluded that significant gender differences in attitudes toward mathematics existed among students of secondary schools in Eldoret municipality and that closure of the sex differential gap could help see girls perform better in mathematics as well. The basis of Owiti's (2011) study provides directions for the current study. It has similar focus to current study. Therefore, apart from the face to face interviews, the questionnaire instrument used is adopted for gathering data on gender differences in the Cape Coast metropolis. The findings from Owiti's (2011) study may be important for empirical comparison with the findings in this current study.

Similar to the study of Kyei et al (2011), Mata, Monteiro and Peixoto, (2012) study on attitudes towardsMathematics: Effects of Individual, Motivational, and Social Support Factors. The aims of the study was to understand how certain different but interrelated variables such as background, motivation, and social support could lead to an explanation of student attitudes towards math and to an understanding of the defining characteristics of theseattitudes in the school environment. Participants consisted of 1719 Portuguese students, from fifth-to-twelfth grade. The studyutilizes an adaptation of the "Intrinsic Motivation Inventory" assessing main determinants of intrinsic motivation. One section ofthe questionnaire- "InmyMath Class"-also assesses student perceptions of teacher and peer support as well as student attitudes.

The results revealed that, in general, students held positive attitudes towards mathematics and also highlighted the main effects ofgrade and math achievement on these attitudes. No gender effect was identified although the girls showed a continuous decline inattitudes the further they progressed in school. A hierarchical analysis using structural equation modeling showed that motivationrelatedvariables are the main predictors of attitudes towards mathematics and that teachers and the social support of peers arealso highly significant in understanding these attitudes. The study by Mata et al (2012), illustrates that gender has no significant effect on attitude towards mathematics. Could this finding be replicated within the current study setting (cape Coast metropolis)? 
More recently in the Ghana National School in the Cape Coast metropolis, Arhin and Offoe, (2015) studied on Gender Differences and Mathematics Achievement of Senior High School Students. A quasi-experimental research method was conducted to find out differences in mathematics performance of students using performance assessment-driven instructions at the senior high school level at Ghana National College inCape Coast. Two Form 1 science classes were used for the study and were assigned as experimental and controlgroups. These two classes were randomly chosen for the study. The experimental group consisted of forty-twostudents and the control group forty students.Data was collected through the use of an open ended test inmathematics. The independent sample ttest and paired sample t-test were used to find the differences betweenthe groups. The experimental group differed significantly on the post-test scores from the control group. Thisstudy identified that PA-driven instruction improved students' problem-solving abilities and showed no biasamong gender. It is recommended that mathematics teachers use PA-driven instructions and performanceassessment task in their mathematics lessons. It is obvious from this study that the focus was on differences in mathematics achievement. The current study expands this by examining the performance of males and females in mathematics

Perhaps the most comprehensive study on gender differences and attitude towards mathematics in recent times is the study conducted by Mutai (2016) in Kenya. This study focused on the gender differences inperformance in mathematics among form three secondary school students in BuretiSub-County. It focused on the influence of students' perception, parental expectations, teachers' characteristics and perceptions and school environment on their learning ofmathematics. The study was a cross-sectional descriptive survey employing correlation methods to investigate gender differences in Mathematics achievementlevels of girls and boys. A total of 430 students responded to a five-item, mathematicsAchievement Test (MAT) comprising statistics and probability questions. DescriptiveSurvey design was used.

Data was collected using Mathematics TeachersQuestionnaires (MTQ) for teachers, Mathematics Students Questionnaire (MSQ) forstudents and Mathematics Students Achievement Test. The target population wasmathematics teachers and form three students from selected secondary schools inBureti Sub-County, Kenya. Stratified sampling technique was used to select eight (8)secondary schools: 2 for boys, 2 for girls and 4 for mixed from 54 secondary schoolsin Bureti Sub-County, Kenya.The study used a sample of four hundred and thirty (430) form three students from the eight stratified and randomly selected secondaryschools. Eighteen mathematics teachers teaching the study classes were purposivelysampled. Simple random sampling was used to select one stream from each categorywhere there were more than one stream, otherwise the stream was purposivelyselected. The instruments were piloted to enhance their validity and reliability.Students did a mathematics test. Data obtained from the study were analyzed usingSPSS software.The students also responded to the Attitude Scale. The teachers filled the Mathematics Teachers Questionnaire (MTQ) on the reasons for poor performanceof students in Mathematics and their possible solutions. The validity and reliability ofthe instruments were enhanced by a pilot study and the adoption of some alreadyvalidated items. A reliability coefficient of at least 0.8 was acceptable for the study.

The study revealed the following findings; gender was strongly associated withmathematics achievement $(\mathrm{r}=$ $0.9880, \mathrm{p}<0.05$ ). As a result, boys' schools performedbetter than girls schools. Boys had a stronger affinity and interest towardsmathematics. Teacher and school factors were of little effect on mathematicsachievement with respect to gender. The key recommendation was that measures areneeded to be taken as early as possible, probably already in primary education, whichaim at the suppression of socialization factors known to lead to the establishment ofgender differences in mathematics achievement. It would be desirable to implementstrategies in the curriculum as well as in the pre and in-service training which wouldhelp moderate gender differences in students' achievement in mathematics.

In likeness to the study by Mutai (2016), the current study has examined its contents and parameters through a careful analysis of Mutai's (2016) study. It has provided a fundamental roadmap in reviewing other related information which examines gender differences in other sectors order than mathematics. Mutai's study provides guidelines to the current study through theoretical analysis and other social factors pertaining to gender differences.

\section{Conceptual Issues:-}

The theoretical and empirical literatures have revealed some relevant concepts which underpin the paper. Thus, lessons from the literature coupled with the focus of this study show that the key concepts for this study are gender difference, gender attitude and mathematics achievement. 


\section{Gender Difference:-}

The literature has revealed that the role played by gender in mathematics education is multifaceted (Barkatsas, Kasimatis\&Gialamas, 2009; Niederle\&Vesterlund, 2010; Zakaria, Chin \&Daud, 2010). This means that different reasons account for gender differences in attititude towards mathematics. The references above show that many reports of differencesin mathematics performance related to gender have been presented over the pastdecades. In these reports, performance differences have been postulated to be due at least in part, toattitudinal differences regarding mathematics.

Niederle and Vesterlund (2010) using the Fennema-Shermanmathematics attitudes scales, which was developed in 1977 found several gender differences inhigh school students' attitude. For the students in those high schools in which themales performed significantly better on mathematics achievement tests, Niederle and Vesterlund (2010) found that males also had higher scores on attitude scales includingconfidence in learning mathematics, viewing mathematics as male domain, attitudetowards success in mathematics, mother's support, father's support and usefulness ofmathematics. Since that initial report, similar gender differences in attitude towardsmathematics have been reported for different ages and using different measurement scales (Devine, Fawcett, Szücs\&Dowker, 2012;Else-Quest, Hydem\& Linn, 2010; Gunderson, Ramirez, Levine, \&Beilock, 2012). Therefore one of the areas that this study seeks to look at is the gender differences in terms of performance through cross-checks on past records of the students in the selected schools in the Cape Coast Metropolis.

\section{Gender Attitude:-}

Gender attitude towards mathematics could be described as self-concept towards mathematics (believes about one's ability to learn and person task). Moreover, mathematics anxiety (feeling of tension that hinder learning processes and performance), attitudes towards mathematics, affective and behavioural engagement contribute to the effectiveness of learning process (Abebe, 2014). Attitude is a central part of human identity. Every day people love, hate, like, favour, oppose, agree, disagree, argue, persuade, etc. All these are evaluative response to an object. Hence, attitudes defined as "A summary of evaluation of an object of thought" (Arhin\&Offoe, 2015). Attitudes towards mathematics can referred to a positive or negative emotional disposition towards mathematics. There have been a lot of studies showing gender attitude towards mathematics in high schools.

Ganley and Vasilyeva (2013) found that females tend to be more anxious towards mathematics than males. It has been shown that anxiety may impact mathematical performance due to the relationship between anxiety and working memory. Prior research suggests that "individuals with high anxiety would perform less efficiently on tasks requiring working memory resources because their worrisome thoughts interfere with working memory. Other researchers had agreed that attitude towards the learning of mathematics becomes increasingly less favourable beginning from the early elementary early junior high school for boys and girls (Kebede, 2007).In addition to this many research studies had been done on comparison between female and male students "attitude towards mathematics and suggested that there is no significant difference between attitude towards mathematics among male and female students (Mohamedd et al, 2011).

Moreover, interest and attitude in the subject area are the special predictors for the students ${ }^{\text {ee }}$ participation and success in the subject Attitude has based on the value and beliefs as well as varying degree of factual knowledge (George \& George 2012). Attitudes towards mathematics can referred to a positive or negative emotional disposition towards mathematics (Riegle-Crumb, Moore \& Ramos-Wada, 2011).According to Karimi and Venkatesan (2009), significant gender differences found in several areas, and attitudes variables found to be useful in predicting grades. In study that involved 847 students of grade, 8 to 11 in North shoa zone Robinson and Lubienski(2011)found no gender difference in attitude towards mathematics among eight graders. None, he found significant gender differences in favor of boys at subsequent grade level $(9,10$ and 11).

Some studies have employed subscale measures of attitudes toward mathematics Devineet al (2012) examined gender difference among junior school students they found significant differences favoring males on two subscales. Other researchers had agreed that attitude towards the learning of mathematics becomes increasingly less favorable beginning from the early elementary early junior high school for boys and girls (Kebede, 2007). In addition to this many research studies had been done on comparison between female and male students "attitude towards mathematics and suggested that there is no significant difference between attitude towards mathematics among male and female students (Mohamedd et al, 2011). This study operationalises attitude using facets such as gender interest, confidence, fear, competence and success 


\section{Mathematics Achievement:-}

Mathematics achievement is the attainment, accomplishment or successfulperformance in a mathematics examination, measured in scores that candidates obtainin an examination (Robinson \&Lubienski2011). Ghana's records show that girls continue to underachieve in mathematics national examinations. In the 2011WASSCE examination results,for instance, girls obtained a lower mathematics performance mean score of $10 \%$ compared to $14 \%$ for boys (Asante, 2012; Mensah, Okyere\&Kuranchie, 2013; Buabeng-Andoh, 2012). Average pass rate for boys 55\% and Girls 44\% in 2012 WASSCE (MOE, 2013). Gender differences in mathematics achievement begin to appear at the upper primary school level and increase in secondary schools (Atnafu, 2010). These differences are caused by an interaction of factors within and outside the school aswell as by the students' background (Adesoji\&Ibraheem, 2009; Yara\& Catherine, 2011).

Students' efforts, ability and their teacher's effectiveness greatly influence their performance in mathematics (Robinson \&Lubienski2011)but, unlike in developed countries whereteaching resources are in abundance, in developing countries mathematicsperformance is influenced more by current factors within a school (Atnafu, 2010).Study done by DénesSzücs (2012) in Britain, has revealed that secondary schoolchildren experience Mathematics Anxiety (MA). Importantly, girls showed higherlevels of MA than boys and high levels of MA were related to poorer levels ofmathematics performance. Potentially having a detrimental effect on 'online'mathematics performance, past research has shown that high levels of MA can havenegative consequences for later mathematics education.

Therefore, MA warrantsattention in the mathematics classroom, particularly because there is evidence thatMA develops during the primary school years. Furthermore, study showed no genderdifference in mathematics performance, despite girls reporting higher levels of MA.These results might suggest that girls may have had the potential to perform betterthan boys in mathematics; however, their achievement may have been attenuated bytheir higher levels of MA. Therefore, the studyintended to find out the genderdifferences in mathematics achievement.

\section{Conceptual Framework:-}

Following the lessons learnt from the literature, vis-à-vis the focus of the study, the study operationals gender differences using five constructs. These are gender interest, gender confidence, gender fear, gender competence and gender success. Each of these constructs measured and assessed in relation to mathematics achievement and subsequently segregate the score between boys and girls. The framework is depicted in Figure 1.

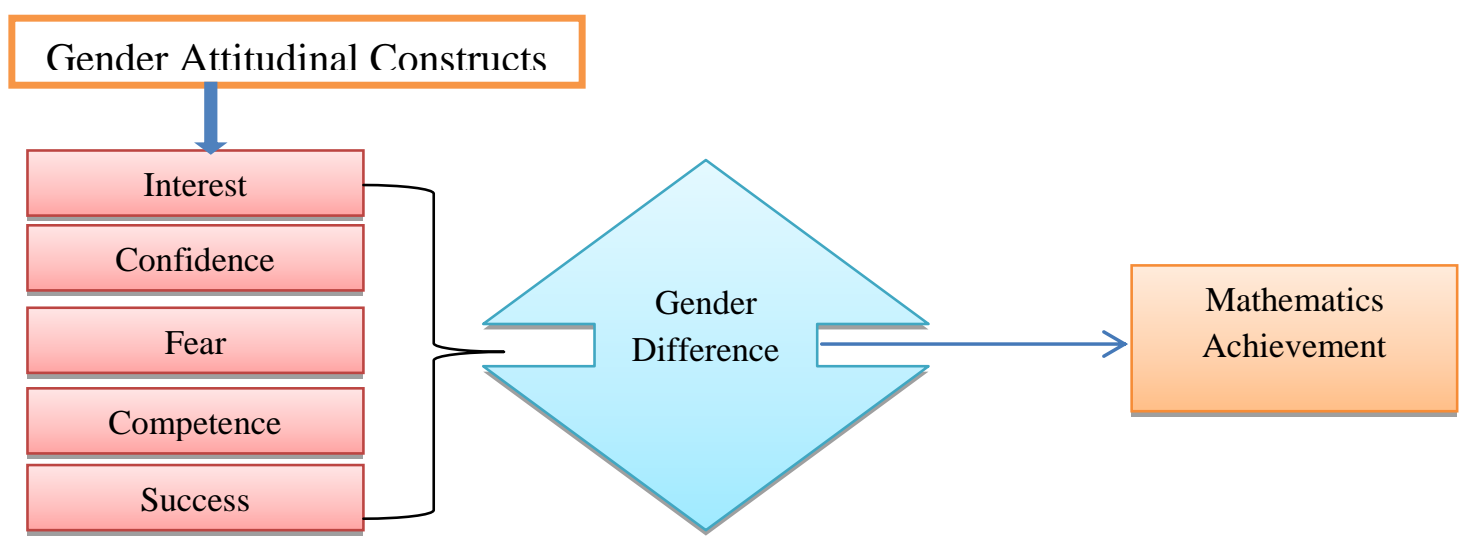

Figure 1:-Framework for Assessing Gender Attitude toward Mathematics Source: Nartey's Construct (2018)

\section{Methodology:-}

This paper uses descriptive survey as the study design. The paper targets twelve (12) senior high schools within the metropolis. The distributions of the schools are three (3) boys school, two girls school and seven (7) mixed school. 
The study uses multi-stage sampling. Specifically, stratified sampling and simple random are used to select 120 samples for the study.Thissample technique is appropriate as it provides the study with the opportunity to collect data from the desired representation of relevant sub-units and could increase the efficiency of the population estimates (Mutai, 2016). The target schools are grouped into three strata: boys, girls and mixed schools. Simple random is subsequently used to select the relevant strata. To apply the simple random, each school within the sample frame is assigned a number. These numbers are written on pieces of papers, folded and placed in three different containers marked as boys, girls and mixed. Thestudy picks at random 4 schools. These are 1 boy school, 1 girl school and 2 schools from eachcontainer.

The data are collected using self-administered questionnaire. The questionnaire contains two sections. The first section covers the general information about the students and the second section captures gender attitudes toward mathematics. The gender attitudes used are gender interest, gender confidence, gender fear, gender competence and gender success. A 4-point Likert Attitudes Scale ranging from "strongly agree" to "strongly disagree" is used to determine students' attitudes towards mathematics. Having designed and collected the relevant data, the study proceeds to the data analysis. The data collected from the field are analysed using descriptive. Frequency and descriptive tables areused in the data analysis. The questionnaire received from the students arescrutinised and coded for SPSS analysis.

\section{Results and Discussions:-}

Subsequent to methodology, the data collected to address the specific objective of the paper. The analysis and results provide findings which form the basis for conclusions and recommendations. The results are reported in tables and figures.

\section{Background Information of the Students:-}

This section addresses and analyses the background information of all the students from the various selected schools. It focuses on age and the type of school (single or mixed).

Table 1:-Age of respondents

\begin{tabular}{|l|l|l|}
\hline Response & Frequency & Percent \\
\hline Less than 15 & 25 & 12.0 \\
\hline $16-19$ & 80 & 80.0 \\
\hline 20 and above & 15 & 8.0 \\
\hline Total & 120 & 100.0 \\
\hline
\end{tabular}

Source: Fieldwork, 2018

Table 1 illustrates that majority of the students fall within the age range of 16-20. This is represented in percentage wise by $80 \%$. The number best fit the normal Ghanaian age for senior high school form two and three students

Table 2:-School Type

\begin{tabular}{|l|l|l|}
\hline Response & Frequency & Percent \\
\hline Boys & 43 & 35.83 \\
\hline Mixed & 35 & 29.17 \\
\hline Girls & 42 & 35.00 \\
\hline Total & 120 & 100.0 \\
\hline
\end{tabular}

Source: Fieldwork, 2018

From Table 2, it could be observed that the 43 of the respondents representing $35.83 \%$ were from boysschool. 42 respondents representing 35\% were from girl schools whiles $29.17 \%$ were from mixed school. Figure 2 presents the pictorial results of the school type.The figure revealed that slightly more than one third of the students came from boys school and girl school. 


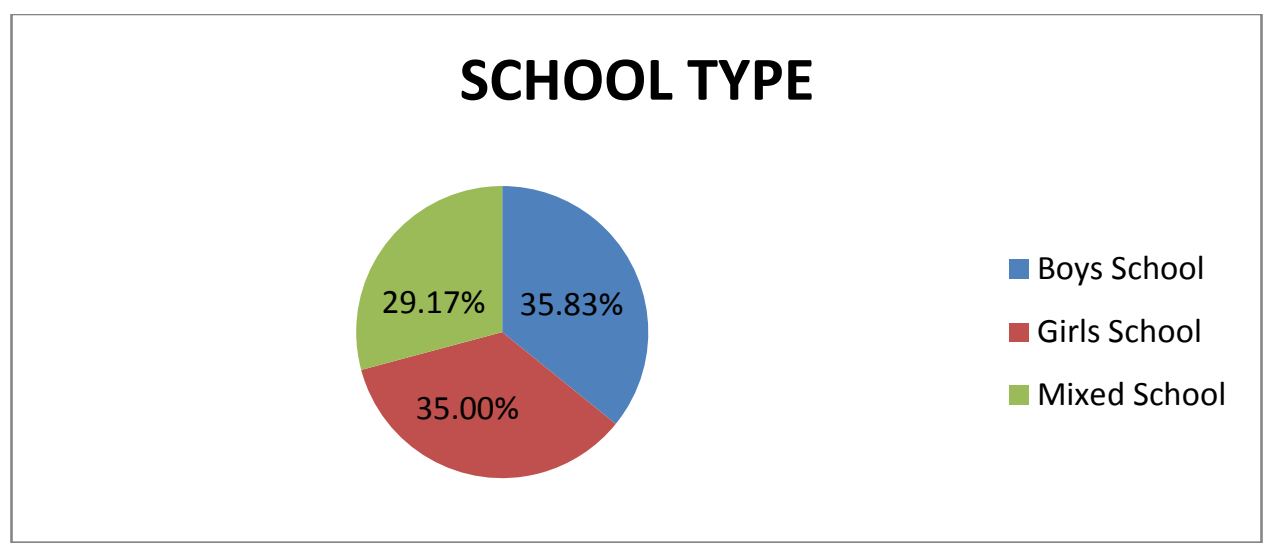

Source: Fieldwork, 2018

Figure 2:-Proportion of School Type

In Figure 3, it is evident that 60 of the respondents, representing $50 \%$ were boys and girls. This was attributed to the fact that equal proportionate sample was assigned so as to present similar comparison in terms gender attitude.

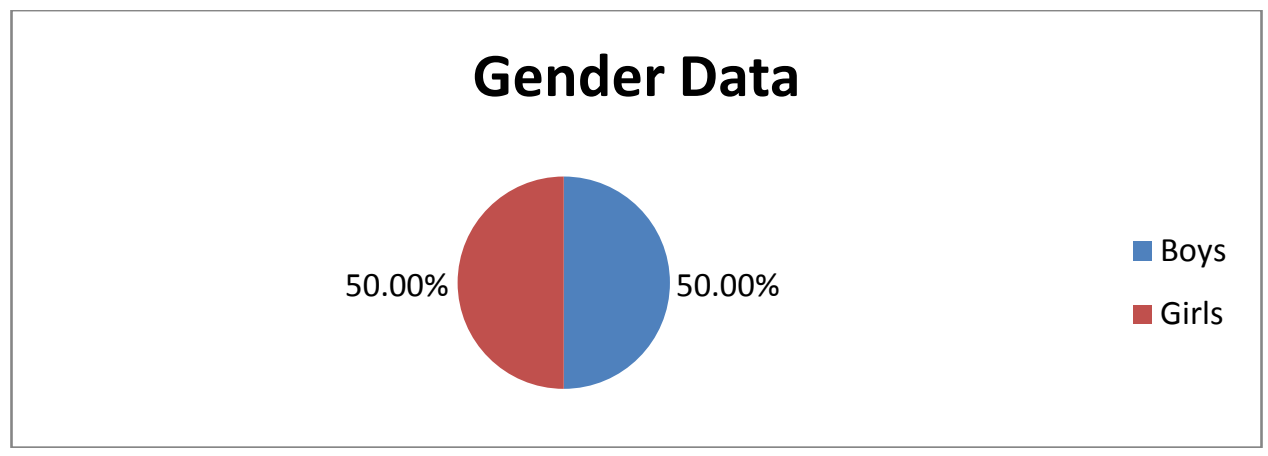

\section{Source: Fieldwork, 2018}

Figure 3:-Gender Distribution of the Data

Differences in Gender Interest in towards Mathematics:-

This section presents information on differences in gender interest as one form of attitude towards the study of mathematics. The results are reported in Table 3.

Table 3:- Differences in gender interest in towards mathematics (females)

\begin{tabular}{|l|l|l|l|l|l|l|l|l|l|}
\hline Responds & SA & A & D & \multicolumn{2}{l|}{ SD } \\
\hline & F & $\%$ & F & $\%$ & F & $\%$ & F & $\%$ \\
\hline I love solving mathematics problems & 15 & 25.0 & 1 & 2.0 & 11 & 18.0 & 33 & 55.0 \\
\hline $\begin{array}{l}\text { My interest in attending mathematics class is } \\
\text { high }\end{array}$ & 13 & 21.0 & 6 & 10.0 & 16 & 27.0 & 25 & 42.0 \\
\hline I really enjoy mathematics lessons & 10 & 16.0 & 5 & 5.0 & 23 & 38.0 & 22 & 37.0 \\
\hline I have interest in mathematics calculations & 17 & 29.0 & 3 & 5.0 & 10 & 16.0 & 30 & 50.0 \\
\hline $\begin{array}{l}\text { I would have still done mathematics if it was not } \\
\text { compulsory }\end{array}$ & 16 & 27.0 & 16 & 27.0 & 12 & 11.0 & 16 & 27.0 \\
\hline
\end{tabular}

\section{Source: Fieldwork, 2018}

From Table 3 it could be observed that many of the females disagree to the fact that they love solving mathematics problems. This could be seen from a combined total of 44 students representing $73 \%$ of the total female respondents. Moreover, 41 of them indicated that they have less interest in attending mathematics classes, representing $69 \%$. 
Furthermore, although 32 of them indicated that they would still offer mathematics even if it was not compulsory, a whopping 40 of the female students representing $66 \%$ of the total population indicate that they have less interest in mathematics calculations. Combining the various responds, it could be observed on the whole that females have less interest in studying mathematics.

Table 4:-Differences in Gender Interest in towards Mathematics (males)

\begin{tabular}{|c|c|c|c|c|c|c|c|c|}
\hline Responds & SA & & A & & $\mathrm{D}$ & & SD & \\
\hline & $\mathrm{F}$ & $\%$ & $\mathrm{~F}$ & $\%$ & $\mathrm{~F}$ & $\%$ & $\mathrm{~F}$ & $\%$ \\
\hline I love solving mathematics problems & 18 & 30.0 & 16 & 27.0 & 16 & 27.0 & 10 & 16.0 \\
\hline My interest in attending mathematics class is high & 21 & 35.0 & 15 & 25.0 & 10 & 16.0 & 14 & 24.0 \\
\hline I really enjoy mathematics lessons & 17 & 29.0 & 21 & 35.0 & 11 & 18.0 & 11 & 18.0 \\
\hline I have interest in mathematics calculations & 24 & 40.0 & 15 & 25.0 & 12 & 11.0 & 9 & 15.0 \\
\hline $\begin{array}{l}\text { I would have still done mathematics if it was not } \\
\text { compulsory }\end{array}$ & 29 & 49.0 & 13 & 22.0 & 10 & 16.0 & 8 & 13.0 \\
\hline
\end{tabular}

\section{Source: Fieldwork, 2018}

From Table 4, the males seem to have high interest in the studies of mathematics. This is because more than half of the total respondents - 34 which represent $57 \%$ of the respondents indicate that they love solving mathematical problems. Similarly, aside the 36 of them ( $60 \%$ of boys) who say they have high interest in attending mathematics class, as many as 38 of the male student which representing $64 \%$ of total male respondents indicated that they enjoy mathematics lesson. Interestingly 39 of the male students which represent $65 \%$ illustrate their interest in mathematical calculations. Lastly a little above average of them (32) indicated that they would have still done mathematics even if it was not compulsory

Comparing the responds of both males and females, it could be observed that the males have high interest in mathematics than the females. This could be seen with respect to their interest in class attendance $36>19$, interest in solving mathematical problems $34>16$ and their interest in mathematical calculations $39>32$. This findings is in line with Owiti, (2011) whose study in Kenya indicated that more boys than girls (93.7\% of boys compared to $59.5 \%$ of girls) had positive attitudes toward mathematics while more girls than boys (35.7\% of girls compared to $6.3 \%$ of boys) were negatively oriented toward mathematics. Another study by Mbuthia(2011) also found that more boys than girls (93.7\% of boys compared to $59.5 \%$ of girls) had positive attitudes toward mathematics while more girls than boys (35.7\% of girls compared to $6.3 \%$ of boys) were negatively oriented toward mathematics. This further affirms the study by Mutai (2016) in Kenya.The study revealed the following findings; gender was strongly associated withmathematics achievement $(r=0.9880, \mathrm{p}<0.05)$. As a result, boys' schools performedbetter than girls schools. Boys had a stronger affinity and interest towardsmathematics. Moreover, on the attitude of interest the information disputes what Robinson and Lubienski(2011) observed. They found no gender difference in attitude towards mathematics among eight graders. They also did not find any significant gender differences in favor of boys at subsequent grade level $(9,10$ and 11$)$.

\section{Differences in Confidence towards Mathematics Study:-}

This part of the study provides empirical evidence from the investigation in this study about differences in gender confidence towards the study of mathematics within the Cape Coast metropolis.

Table 5:-Differences in Gender Confidence towards Mathematics (females)

\begin{tabular}{|c|c|c|c|c|c|c|c|c|}
\hline Responds & \multicolumn{2}{|c|}{ SA } & \multicolumn{2}{|l|}{ A } & \multicolumn{2}{|l|}{$\mathrm{D}$} & \multicolumn{2}{|l|}{ SD } \\
\hline & $\mathrm{F}$ & $\%$ & $\mathrm{~F}$ & $\%$ & $\mathrm{~F}$ & $\%$ & $\mathrm{~F}$ & $\%$ \\
\hline $\begin{array}{l}\text { I have confidence in problems that } \\
\text { involvesubstituting numbers into formulas }\end{array}$ & 5 & 8.0 & 5 & 8.0 & 21 & 35.0 & 29 & 49.0 \\
\hline $\begin{array}{l}\text { I have confidence in purely numerical } \\
\text { computations }\end{array}$ & 4 & 7.0 & 12 & 20.0 & 18 & 30.0 & 26 & 43.0 \\
\hline I have confidence in solving word problems & 5 & 8.0 & 12 & 20.0 & 17 & 29.0 & 26 & 43.0 \\
\hline $\begin{array}{l}\text { I have confidence in answering mathematics } \\
\text { question in class }\end{array}$ & 6 & 10.0 & 9 & 15.0 & 24 & 40.0 & 21 & 35.0 \\
\hline I would have confidence in telling the teacher my & 10 & 16.0 & 12 & 20.0 & 18 & 30.0 & 20 & 33.0 \\
\hline
\end{tabular}


problems in mathematics

\section{Source: Fieldwork, 2018}

It could be observed from Table 5 that 50 females out of the 60 sampled have no confidence in problems solving which involve substitution of formulas. This number constitutes $84 \%$ of the total respondents. Moreover, $75 \%$ of the females which in nominal terms constitute 45 females indicate that they have little confidence in answering mathematics question in class. It could further be observed that very few of them (22) have the confidence in telling the teacher their problems in mathematics whereas 44 of them representing $73 \%$ lack confidence in purely numerical computations. It could thus be inferred from these numbers and percentages that the level of confidence in mathematics from the perspective of females is low.

Table 6:-Differences in gender confidence towards mathematics (males)

\begin{tabular}{|c|c|c|c|c|c|c|c|c|}
\hline Responds & \multicolumn{2}{|l|}{ SA } & \multicolumn{2}{|l|}{ A } & \multicolumn{2}{|l|}{$\mathrm{D}$} & \multicolumn{2}{|c|}{ SD } \\
\hline & $\mathrm{F}$ & $\%$ & $\mathrm{~F}$ & $\%$ & $\mathrm{~F}$ & $\%$ & $\mathrm{~F}$ & $\%$ \\
\hline $\begin{array}{l}\text { I have confidence in problems that } \\
\text { involvesubstituting numbers into formulas }\end{array}$ & 16 & 23.0 & 17 & 29.0 & 12 & 20.0 & 15 & 25.0 \\
\hline $\begin{array}{l}\text { I have confidence in purely numerical } \\
\text { computations }\end{array}$ & 20 & 33.0 & 19 & 32.0 & 7 & 12.0 & 14 & 23.0 \\
\hline I have confidence in solving word problems & 21 & 35.0 & 17 & 29.0 & 14 & 23.0 & 8 & 5.0 \\
\hline $\begin{array}{l}\text { I have confidence in answering mathematics } \\
\text { question in class }\end{array}$ & 18 & 30.0 & 17 & 29.0 & 15 & 25.0 & 10 & 16.0 \\
\hline $\begin{array}{l}\text { I would have confidence in telling the teacher my } \\
\text { problems in mathematics }\end{array}$ & 22 & 28.0 & 14 & 23.0 & 14 & 23.0 & 10 & 16.0 \\
\hline
\end{tabular}

\section{Source: Fieldwork, 2018}

From Table 6 it could be observed that unlike their female counterpart, 33 of the male students have confidence in problems that involvesubstituting numbers into formulas. This number is equal to $52 \%$ of the total respondents. Similarly, 39 of the males which constitute $65 \%$ of the total males sampled have confidence in purely numerical computations. Additionally, 35 of the male students indicated that they have confidence in answering mathematics question in class. Moreover, 38 of the males which represent $64 \%$ of the total male population have confidence in solving word problems. However, 36 of the males which constitute $51 \%$ also indicated that they lack the confidence in telling the teacher my problems in mathematics

Comparing the gender confidence in the study of mathematics, it could be observed that males, from the information presented in Tables 5 and 6 lack confidence in telling the teacher their problems in mathematics as compared to their female counterpart. This is because while only 22 females lack the confidence more than 50\% (36) males lack such confidence. Aside the confidence to telling the teacher their problems in mathematics, males seems to have confidence in almost all of the items cited. For instance while $73 \%$ of the females lack confidence in purely numerical computation, $65 \%$ of the males have confidence in purely numerical computation. Furthermore, while $59 \%$ of the males have confidence in answering questions in mathematics class, $75 \%$ of the females lack the confidence of answering questions in mathematics class. This thus gives the indication that males are more confidence that females in mathematics within the study area. Similary, Niederle and Vesterlund (2010) found that males also had higher scores on attitude scales includingconfidence in learning mathematics,

\section{Gender Differences in Competence towards Mathematics Study:-}

Gender competence is one of the attitudinal constructs and has been employed to investigate differences in gender attitude with respect to the study of mathematics.

Table 7:-Gender Differences in Competence towards Mathematics (females)

\begin{tabular}{|c|c|c|c|c|c|c|c|c|}
\hline Responds & \multicolumn{2}{|c|}{ SA } & \multicolumn{2}{|l|}{$\mathrm{A}$} & \multicolumn{2}{|l|}{$\mathrm{D}$} & \multicolumn{2}{|c|}{ SD } \\
\hline & $\mathrm{F}$ & $\%$ & $\mathrm{~F}$ & $\%$ & $\mathrm{~F}$ & $\%$ & $\mathrm{~F}$ & $\%$ \\
\hline $\begin{array}{l}\text { I fully understand the content in the mathematics } \\
\text { class }\end{array}$ & 4 & 7.0 & 4 & 7.0 & 23 & 38.0 & 29 & 48.0 \\
\hline Usually I fully understand word problems & 2 & 3.0 & 18 & 30.0 & 13 & 22.0 & 27 & 45.0 \\
\hline I have difficulty in solving word problems & 21 & 35.0 & 16 & 27.0 & 15 & 25.0 & 8 & 13.0 \\
\hline
\end{tabular}




\begin{tabular}{|l|l|l|l|l|l|l|l|l|}
\hline $\begin{array}{l}\text { Though I know how to calculate, sometimes I } \\
\text { don't know why this is so }\end{array}$ & 19 & 13.0 & 20 & 33.0 & 13 & 22.0 & 8 & 13.0 \\
\hline $\begin{array}{l}\text { I consider mathematics as one of the easiest } \\
\text { subject. }\end{array}$ & 10 & 16.0 & 14 & 23.0 & 14 & 23.0 & 22 & 37.0 \\
\hline
\end{tabular}

\section{Source: Fieldwork, 2018}

From Table 7 it is clear that very few (8) of the female respondents fully understand content in the mathematics class. This means that many of them do not actually comprehend the various mathematical lessons that are taught in class. There is therefore little wonder that 45 of them representing $75 \%$ indicated in Table 3 that they do not enjoy mathematics lessons. Moreover, many of the female students do not understand word problems. This is substantiated by 40 of the female students which comprise $65 \%$ of the total respondents. Furthermore, aside the 37 students who find it difficult in solving word problems, $60 \%$ of the females disagree to the fact that mathematics is one of the easiest subjects.

Table 8: Gender Differences in Competence towards Mathematics (males)

\begin{tabular}{|l|l|l|l|l|l|l|l|l|}
\hline Responds & SA & A & D & \multicolumn{2}{l|}{ SD } \\
\hline & $\mathrm{F}$ & $\%$ & $\mathrm{~F}$ & $\%$ & $\mathrm{~F}$ & $\%$ & $\mathrm{~F}$ & $\%$ \\
\hline $\begin{array}{l}\text { I fully understand the content in the mathematics } \\
\text { class }\end{array}$ & 4 & 7.0 & 13 & 22.0 & 26 & 43.0 & 17 & 28.0 \\
\hline Usually I fully understand word problems & 15 & 25.0 & 4 & 7.0 & 9 & 15.0 & 32 & 53.0 \\
\hline I have difficulty in solving word problems & 21 & 35.0 & 16 & 27.0 & 15 & 25.0 & 8 & 13.0 \\
\hline $\begin{array}{l}\text { Though I know how to calculate, sometimes I } \\
\text { don't know why this is so }\end{array}$ & 4 & 7.0 & 13 & 22.0 & 26 & 43.0 & 17 & 28.0 \\
\hline $\begin{array}{l}\text { I consider mathematics as one of the easiest } \\
\text { subject. }\end{array}$ & 22 & 37.0 & 14 & 23.0 & 14 & 23.0 & 10 & 16.0 \\
\hline
\end{tabular}

\section{Source: Fieldwork, 2018}

From Table 8, most of the males (43) confirm that they do not fully understand the content in mathematics class. This could be seen as $71 \%$ of the student disagree that they fully understand the content taught in class. This is followed by their understanding of word problems. With respect to this too (understand word problems), $68 \%$ of the males indicate that they do not fully understand. It is therefore not surprising as 37 of the males representing $62 \%$ of the total male respondents indicated that they have difficulty in solving word problems. However, the number of males who agree that mathematics is one of the easiest subjects is 12 more than those who disagree. This is because while 36 of the males agree that mathematics is easy only 24 disagree that is one of the easiest subjects.

It could be inferred from Tables 7 and 8 that both males and females have little confidence in the study of mathematics. This is because from the tables, both sexes demonstrated that they do not fully understand content taught in mathematics class, do not fully understand word problems and also have difficulty in solving word problems. In all these areas the number of students who demonstrated their lack of confidence outnumbered those who indicated that they have confidence in them.

\section{Gender Differences in Fear towards Mathematics Study:-}

Fear is another attitudinal factor which determines gender difference in the study of mathematics. This study assesses the level of students fear towards the study of mathematics by segregating the results into boys and girls. The statistical results are reported in Table 9.

Table 9: Gender Differences in Fear towards Mathematics (Females)

\begin{tabular}{|l|l|l|l|l|l|l|l|l|}
\hline Responds & SA & A & D & \multicolumn{2}{l|}{ SD } \\
\hline & F & $\%$ & F & $\%$ & F & $\%$ & F & $\%$ \\
\hline I am afraid to ask questions in math class & 16 & 27.0 & 23 & 38.0 & 15 & 25.0 & 6 & 10.0 \\
\hline I fear math tests more than any other kind & 25 & 42.0 & 12 & 20.0 & 9 & 15.0 & 14 & 23.0 \\
\hline $\begin{array}{l}\text { I am always worried about being called on in } \\
\text { math class }\end{array}$ & 26 & 43.0 & 14 & 23.0 & 12 & 20.0 & 8 & 13.0 \\
\hline $\begin{array}{l}\text { I am uneasy about going to the board in a math } \\
\text { class }\end{array}$ & 15 & 25.0 & 24 & 40.0 & 14 & 23.0 & 7 & 12.0 \\
\hline
\end{tabular}




\begin{tabular}{|l|l|l|l|l|l|l|l|l|}
\hline I shiver when I have to go to math class. & 30 & 50.0 & 23 & 38.0 & 5 & 8.0 & 3 & 4.0 \\
\hline
\end{tabular}

\section{Source: Fieldwork, 2018}

The results show that 53 which represent $88 \%$ of the total female respondents shiver whenever; they have to go the mathematics class. These in simple terms indicate that they fear going to maths class. Moreover much as many as 37 (62\%) them fear mathematics test than any other test, $40(66 \%)$ always feel worried about being called in mathematics class. Lastly, it could be observed that 39 of the female respondents which represent $65 \%$ of the entire female population indicate that they fear asking questions in class, same percentage of the female indicate that they feel uneasy going to solve mathematics question on the board.

Table 10:-Gender Differences in Fear towards Mathematics (Males)

\begin{tabular}{|c|c|c|c|c|c|c|c|c|}
\hline Responds & \multicolumn{2}{|l|}{$\overline{\text { SA }}$} & \multicolumn{2}{|l|}{ A } & \multicolumn{2}{|l|}{$\mathrm{D}$} & \multicolumn{2}{|c|}{ SD } \\
\hline & $\mathrm{F}$ & $\%$ & $\mathrm{~F}$ & $\%$ & $\mathrm{~F}$ & $\%$ & $\mathrm{~F}$ & $\%$ \\
\hline I am afraid to ask questions in math class & 7 & 12.0 & 8 & 13.0 & 15 & 25.0 & 30 & 50.0 \\
\hline I fear math tests more than any other kind & 7 & 12.0 & 8 & 13.0 & 15 & 25.0 & 30 & 50.0 \\
\hline $\begin{array}{l}\text { I am always worried about being called on in math } \\
\text { class }\end{array}$ & 3 & 4.0 & 7 & 12.0 & 25 & 42.0 & 25 & 42.0 \\
\hline I am uneasy about going to the board in a math class & 15 & 25.0 & 24 & 40.0 & 14 & 23.0 & 7 & 12.0 \\
\hline I shiver when I have to go to math class. & 4 & 7.0 & 3 & 5.0 & 23 & 38.0 & 30 & 50.0 \\
\hline
\end{tabular}

\section{Source: Fieldwork, 2018}

From Table 10, it is found that only $15(25 \%)$ of the male respondents fear asking question in the mathematics class. This means that $75 \%$ of the male respondents do not fear asking questions in the mathematics class. Moreover, same number of male respondents indicates that they have less fear for mathematics test. Again as many as $84 \%$ of the male total respondents state that they do not have any worry for being called in mathematics class. Similarly, $88 \%$ of the male respondents indicate that they do not shiver going to the mathematics class. However, $65 \%$ of the male respondents indicated that they feel uneasy going to the board in math class.

There is no denying fact that females' level of fear in mathematics is higher than males. The number of frequencies and percentages as could be observed in Tables 9 and 10 clearly depict this assertion. From the tables, while $88 \%$ of the females shiver going to mathematics class, equally $88 \%$ of their male counterpart do not shiver at all whenever going to the mathematics class. Moreover $75 \%$ of males do not fear asking questions in math class but $65 \%$ of the females fear asking questions in mathematics class. Furthermore, while $82 \%$ of the males do not feel t worry for being called in maths class, $66 \%$ of the females feel worry when they are called in the maths class. This observation confirms what Ganley and Vasilyeva (2013) revealed. They found that females tend to be more anxious towards mathematics than males. It has been shown that anxiety may impact mathematical performance due to the relationship between anxiety and working memory.

\section{Gender Differences in Success towards Mathematics Study:-}

It is believed that the level of success made toward studying mathematics may be affected by gender difference. Therefore, this paper assesses the level of success toward mathematics from the perspective of boys and girls. Table 11 depicts the results from the investigation.

Table 11:-Gender Differences in Success towards Mathematics (Females)

\begin{tabular}{|c|c|c|c|c|c|c|c|c|}
\hline Responds & SA & & A & & $\mathrm{D}$ & & SD & \\
\hline & $\mathrm{F}$ & $\%$ & $\mathrm{~F}$ & $\%$ & $\mathrm{~F}$ & $\%$ & $\mathrm{~F}$ & $\%$ \\
\hline I able to get good grades in math test & 7 & 12.0 & 8 & 13.0 & 15 & 25.0 & 30 & 50.0 \\
\hline I usually answer questions correct in math class & 7 & 12.0 & 8 & 13.0 & 15 & 25.0 & 30 & 50.0 \\
\hline $\begin{array}{l}\text { I will continue reading mathematics in the } \\
\text { university }\end{array}$ & 3 & 4.0 & 7 & 12.0 & 25 & 42.0 & 25 & 42.0 \\
\hline $\begin{array}{l}\text { My performance in mathematics keeps improving } \\
\text { year after year }\end{array}$ & 13 & 22.0 & 7 & 12.0 & 14 & 23.0 & 26 & 43.0 \\
\hline
\end{tabular}

\section{Source: Fieldwork, 2018}

Table 11, it could be observed that the success rate of females in mathematics is low. This could be seen in their grades, ability to answer questions correctly in class and the desire to continue reading mathematics in the 
university. Moreover, the performance of the females in mathematics sees no considerable improvement from year to year. This is substantiated by $66 \%$ of the total respondents who indicated that their performance does not keep improving year on year.

Table 12:-Gender Differences in Success towards Mathematics (Males)

\begin{tabular}{|c|c|c|c|c|c|c|c|c|}
\hline Responds & \multicolumn{2}{|l|}{$\mathrm{SA}$} & \multicolumn{2}{|l|}{$\mathrm{A}$} & \multicolumn{2}{|l|}{$\mathrm{D}$} & \multicolumn{2}{|c|}{ SD } \\
\hline & $\mathrm{F}$ & $\%$ & $\mathrm{~F}$ & $\%$ & $\mathrm{~F}$ & $\%$ & $\mathrm{~F}$ & $\%$ \\
\hline I am able to get good grades in math test & 16 & 27.0 & 36 & 60.0 & 6 & 10.0 & 2 & 3.0 \\
\hline I usually answer questions correct in math class & 25 & 42.0 & 25 & 42.0 & 6 & 10.0 & 4 & 8.0 \\
\hline I will continue reading mathematics in the university & 36 & 60.0 & 16 & 27.0 & 2 & 3.0 & 6 & 10.0 \\
\hline $\begin{array}{l}\text { My performance in mathematics keeps improving } \\
\text { year after year }\end{array}$ & 14 & 25.0 & 21 & 40.0 & 16 & 27.0 & 9 & 15.0 \\
\hline
\end{tabular}

Source: Fieldwork, 2018

From Table 12, it could be observed that 52 males representing $87 \%$ of the male respondents are able to score good grades in mathematics test. This is followed by $84 \%$ of the males who indicates that they are able to answer questions correctly in a mathematics class. Furthermore, 52 male students' constituting $87 \%$ of the total male respondents indicates that they will continue reading mathematics even in the university whereas many of them illustrate improvement in their performance year after year.

Comparing the success rate too, it is obvious that males are more successful in mathematics study than females. This comparison resonates with the study conducted by Mata, Monteiro and Peixoto, (2012). The results revealed that, in general, students held positive attitudes towards mathematics and also highlighted the main effects ofgrade and math achievement on these attitudes. No gender effect was identified although the girls showed a continuous decline inattitudes the further they progressed in school.Similarly the information affirms the study by Niederle and Vesterlund (2010) from where it was revealed that for the students the high schools where their study was conducted themales performed significantly better on mathematics achievement tests,

\section{Conclusions and Recommendations:-}

The study used five attitudinal gender constructs: gender interest, gender confidence, gender fear, gender competence and gender success to investigate gender attitude towards the study of mathematics in some secondary schools in the Cape Coast metropolis. The relevant conclusions are drawn: that males score higher grades than females and hence harbour the desire to continue reading mathematics in the university. Moreover, it was revealed that males were more able to answer questions correct in math class than females. Based on these findings, it could be seen that males are more successful than females with regards to the study of mathematics.

It is therefore concluded based on the success rate that males perform better in mathematics than females in the Cape Coast Metropolis. However, it was also revealed that both males and females do not fully understand word problems and also have difficulty in solving word problems. This means that in the area of competence both sexes are not significantly different. Except gender competence which was revealed to have no significance in terms gender, it is concluded that males (boys) have more positive attitude towards the study of mathematics than females (girls). The gender differences in attitude are more pronounced in terms of gender interest, gender fear, gender competence and gender success.

It is therefore suggested that gender attitudinal factors such as gender interest, gender confidence, gender fear, and gender success could be considered as important dimensions for educational policy. Instructional methods in teaching and learning mathematics in schools should be gender biased. Thus, it is recommended that special instructional attention should be given to females (girls) to encourage and water appetite for mathematics.It is suggested that more attention should be given to girls in mathematic class. Teachers of mathematics are encouraged to varying their teachings to accommodate these gender differences so that gender balance performance could be reached. 


\section{Reference:-}

1. Abebe, F. (2014). Students' Attitude towards Mathematics, their Achievement and Factors Affecting their Learning in Government General Secondary Schools of Adama City (Doctoral dissertation, Addis Ababa University).

2. Adesoji, F. A., \&Ibraheem, T. L. (2009). Effects of student teams-achievement divisions strategy and mathematics knowlegde on learning outcomes in chemical kinetics. The Journal of International Social Research, 2(6), 15-25.

3. Arhin, A. K., \&Offoe, A. K. (2015). Gender Differences and Mathematics Achievement of Senior High School Students: A Case of Ghana National College. Journal of Education and Practice, 6(33), 67-74..

4. Ajai, J. T., \&Imoko, B. I. (2014). Gender differences in mathematics achievement and retention scores: A case of problem-based learning method. International Journal of Research in Education and Science, 1(1), 45-50.

5. Asante, K. O. (2012). Secondary students' attitudes towards mathematics. IFE Psychologia: An International Journal, 20(1), 121-133.

6. Asante, K. O. (2010). Sex Differences in Mathematics Performance among Senior High Students in Ghana.Gender and Behaviour, 8(2), 3279 - 3289.

7. Atnafu, M. (2010).Relation between Tenth Grade Students' Attitude and Components of Attitude in Algebra with Algebra Achievement of Addis Ababa Secondary Schools, Ethiopia. International Journal for Mathematics Teaching \& Learning.

8. Battey, D. (2013). "Good" mathematics teaching for students of color and those in poverty: the importance of relational interactions within instruction. Educational Studies in Mathematics, 82(1), 125-144.

9. Barkatsas, A. T., Kasimatis, K., \&Gialamas, V. (2009). Learning secondary mathematics with technology: Exploring the complex interrelationship between students' attitudes, engagement, gender and achievement. Computers \& Education, 52(3), 562-570.

10. Beck, A. T., \&Haigh, E. A. (2014). Advances in cognitive theory and therapy: The generic cognitive model*. Annual Review of Clinical Psychology, 10, 1-24.

11. Boyer, C. B., \&Merzbach, U. C. (2011). A history of mathematics.John Wiley \& Sons.

12. Buabeng-Andoh, C. (2012). Factors influencing teachers' adoption and integration of information and communication technology into teaching: A review of the literature. International Journal of Education and Development using Information and Communication Technology, 8(1), 136.

13. Devine, A., Fawcett, K., Szücs, D., \&Dowker, A. (2012). Gender differences in mathematics anxiety and the relation to mathematics performance while controlling for test anxiety. Behavioral and brain functions, $8(1), 33$.

14. Eagly, A. H., \& Wood, W. (2011).Social role theory. Handbook of theories in social psychology, 2, 458-476.

15. Else-Quest, N. M., Hyde, J. S., \& Linn, M. C. (2010). Cross-national patterns of gender differences in mathematics: a meta-analysis

16. English, L. D., \&Kirshner, D. (2015). Handbook of international research in mathematics education.Routledge.

17. Ganley, C. M., \&Vasilyeva, M. (2013).The role of anxiety and working memory in genderdifferences in mathematics.Journal Of Educational Psychology, doi:10.1037/a0034099

18. Gunderson, E. A., Ramirez, G., Levine, S. C., \&Beilock, S. L. (2012).The role of parents and teachers in the development of gender-related math attitudes. Sex Roles, 66(3-4), 153-166.

19. Hlalele, D. (2012). Exploring rural high school learners' experience of mathematics anxiety in academic settings. South African Journal of Education, 32(3), 267-278.

20. Karimi, A., \&Venkatesan, S. (2009). Mathematics anxiety, mathematics performance and academic hardiness in high school students. International Journal of Educational Sciences, 1(1), 33-37.

21. Kebede T. (2007) A comparative study of private and government secondary school Students"e attitude towards mathematics and their mathematics Achievement the case of Adama city. Unpublished Master thesis.Addis Ababa University.

22. Kosgei, A. K., \&Bii.J. (2007). Gender Differences and Attitude Towards Learning ofMathematics Among Secondary Students in Keiyo District.International Journal of Educational Development, 22(1), 1-9.

23. Kyei, L., Apam, B., \&Nokoe, K. S. (2011). Some gender differences in performance in senior high mathematics examinations in mixed high schools. Am. J. Soc. Mgmt. Sci, 2(4), 348-355.

24. Mata, M. D. L., Monteiro, V., \&Peixoto, F. (2012). Attitudes towards mathematics: Effects of individual, motivational, and social support factors. Child development research, 2012.

25. Mbuthia, A. N. (2011). Differences in Mathematics Performance among Secondary

26. School Students.Unpublished M.ED Thesis KenyattaUniversity,Nairobi, Kenya.

27. Mensah, J. K., Okyere, M., \&Kuranchie, A. (2013). Student attitude towards mathematics and performance: Does the teacher attitude matter. Journal of Education and Practice, 4(3), 132-139. 
28. Mohd, N., Mahmood, T. F. P. T., \& Ismail, M. N. (2011).Factors that influence students in mathematics achievement. International Journal of Academic Research, 3(3), 49-54.

29. Mohamed, L., \&Waheed, H. (2011).Secondary students' attitude towards mathematics in a selected school of Maldives. International Journal of humanities and social science, 1(15), 277-281.

30. Mohamed \& Ismael (2011). Secondary students"e attitude towards mathematics in selected school of Maldives. International Journal of humanities and social science V1 No 15 International University of Malaysia.

31. Mutai, C. C. (2016). Gender differences in mathematics performance among secondary school students in Bureti Sub-County, Kericho County Kenya (Doctoral dissertation, Kenyatta University).

32. Niederle, M., \&Vesterlund, L. (2010).Explaining the gender gap in math test scores: The role of competition. The Journal of Economic Perspectives, 24(2), 129-144.

33. Oludipe, D. I. (2012). Gender difference in Nigerian junior secondary students' academic achievement in basic science. Journal of Educational and Social Research, 2(1), 93-99.

34. Owiti, D. S. (2011). Students' sex and attitudes toward mathematics: A case of secondary school students in Eldoret municipality, UasinGishu district, Kenya. International Journal of Educational Research and Technology, 2(2), 56-61.

35. Pahlke, E., Hyde, J. S., \& Allison, C. M. (2014). The effects of single-sex compared with coeducational schooling on students' performance and attitudes: A meta-analysis.

36. Robinson, J. P., \&Lubienski, S. T. (2011). The development of gender achievement gaps in mathematics and reading during elementary and middle school: Examining direct cognitive assessments and teacher ratings. American Educational Research Journal, 48(2), 268-302.

37. Riegle-Crumb, C., Moore, C., \& Ramos-Wada, A. (2011). Who wants to have a career in science or math? Exploring adolescents' future aspirations by gender and race/ethnicity. Science Education, 95(3), 458-476.

38. Stevens, A. L. (2013). A cognitive theory of inquiry teaching. Instructional design theories and models: An overview of their current status, 247.

39. Yara, P. O., \& Catherine, W. W. (2011). Performance determinants of Kenya certificate of secondary education (KCSE) in mathematics of secondary schools in Nyamaiya division, Kenya. Asian Social Science, 7(2), 107.

40. Zakaria, E., Chin, L. C., \&Daud, M. Y. (2010).The effects of cooperative learning on students' mathematics achievement and attitude towards mathematics. Journal of social sciences, 6(2), 272-275. 